\title{
О РЕАКЦИЯХ ПРЕВРАЩЕНИЯ ТЕРПЕНОВЫХ ГАЛОГЕНОПРОИЗВОДНЫХ АЛЛИЛЬНОГО СТРОЕНИЯ В ОКСИПРОИЗводНЫЕ
}

\begin{abstract}
Терпеновые галогенопроизводные с целью изучения их изомерного состава многие исследователи превращали в оксипроизводные, которые затем были разделены и идентифицированы различными способами $\left[{ }^{1-5}\right]$. В случае галогенопроизводных аллильного строения часто наблюдались реакции аллильной перегруппировки, а также циклизация и дегидрохлорирование, что приводило к разноречивым результатам и выводам различных авторов.
\end{abstract}

В настоящей работе с целью выяснения направлений протекания указанных реакций с терпеновыми галогенопроизводными аллильного строения изучались обменные реакции чистых геранил-, нерил- и линалилхло ридов с водой, метилатом натрия и ацетатом калия.

Исходными веществами служили чистые изомеры галогенопроизводных, полученные нами ранее [6, $]$. Состав продуктов реакции определялся методом газовой хроматографии $\left.{ }^{8}\right]$ с использованием «меток» индивидуальных производных заведомой чистоты.

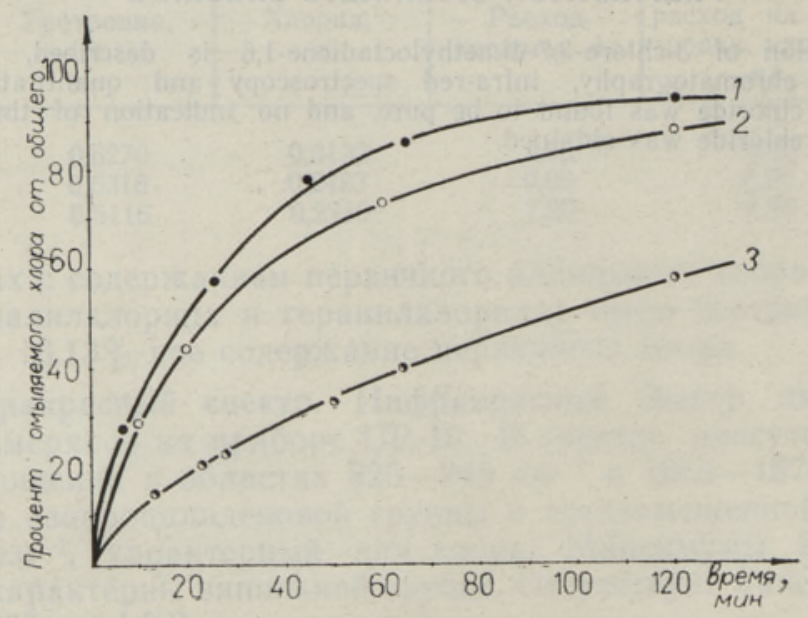

Рис. 1. Кинетика омыления хлоридов.

1 - лнналилхлорид, 2 - нерилхлорид, 3 - гераннлхлорид.

Результаты изучения кинетики реакции омыления отдельных галогенопроизводных в водно-ацетоновом растворе в присутствии $\mathrm{NaHCO}_{3}$ приведены на рис. 1. 
Математический анализ полученных результатов позволяет сделать вывод, что кинетическое уравнение данных реакции в изучаемых концентрационных пределах приобретает общий вид

$$
\frac{d x}{d t}=-\frac{k x}{\frac{1}{k_{0}}\left(x_{0}-x\right)+1}
$$

Әто указывает на то, что образуемые продукты (спирты) снижают в течение реакции активность ионов воды и тем самым замедляют видимую скорость реакции первого порядка. Вычислены значения суммарных кинетических констант реакции омыления при $T=20^{\circ} \mathrm{C}$ и $x_{0}=0,04$ моль/. * Для геранилхлорида $k=0,27 \cdot 10^{-3} \mathrm{ce \kappa}-1, k_{0}=1,0 \cdot 10^{-2}$ моль $/ \Omega$, для нерилхлорида $k=1,0 \cdot 10^{-3}$ сек ${ }^{-1}, k_{0}=1,18 \cdot 10^{-2}$ моль/л, для линалилхлорида $k=1,4 \cdot 10^{-3}$ сек-1, $k_{0}=1,33 \cdot 10^{-2}$ моль $/ \Omega$, где $k$ - суммарная константа псевдомономолекулярной реакции омыления и $k_{0}-$ константа равновесия продуктов реакции с ионами воды $\left(\mathrm{H}_{3} \mathrm{O}^{+}\right.$или $\left.\mathrm{OH}^{-}\right)$.

В табл. 1 приведены результаты реакций омыления хлорпроизводных при различной $\mathrm{pH}$ среды в водных растворах, гомогенизированных органическими растворителями. Основными продуктами реакции нерилхлорида является терпинеол, линалоол и терпены. Следовательно, гидролиз нерилхлорида сопровождается аллильной перегруппировкой, реакциями циклизации и дегидрохлорирования. Последние протекают значительно быстрее, чем в случае его транс-изомера - геранилхлорида []. Гидролиз линалилхлорида протекает без аллильной перегруппировки с частичной циклизацией и с дегидрохлорированием при $\mathrm{pH}<7$. В случае применения в качестве растворителя спиртов наблюдается образование в значительном количестве простых эфиров, в особенности в кислой среде. Ранее было высказано предположение [5], что образование эфиров из первичных аллильных хлоридов протекает без аллильной перегруппировки, а из третичных образуются смеси изомерных зфиров. Сопоставление хроматограмм метильных эфиров, синтезированных нами из геранил-, нерил- и линалилхлоридов, приводит к аналогичному выводу (табл. 2).

Обменная реакция первичных хлоридов с ацетатом калия в ацетоне протекает сравнительно медленно, в диметилформамиде [10] образование ацетатов идет гладко и без аллильной перегруппировки. В качестве конечных продуктов нами были выделены геранилацетат 87,5\%-ной и нерилацетат $86,0 \%$-ной чистоты. Попытки синтеза линалилацетата в подобных условиях выявили, что линалилхлорид почти не взаимодействует с ацетатом калия в примененных условиях.

В результате исследования можно заключить, что омыление изомерных аллильных терпеновых хлорпроизводных в водной среде в случае первичных изомеров сопровождается почти полной аллильной перегруппировкой, а с третичными изомерами протекает без нее. Омыление первичного цис- и третичного изомеров сопровождается реакциями циклизации и дегидрохлорирования, в особенности в кислой среде. Соотношение скоростей реакции омыления изомеров транс-первичный : цис-первичный : третичный равняется $1: 3,8: 5,2$. Применение в качестве растворителя спиртов приводит к образованию простых эфиров, в особенности в кислой среде. Реакция метилата натрия с первичными изомерами, наоборот, протекает с незначительной аллильной перегруппировкой, в случае третичного изомера образуется значительное количество

* Авторы благодарят Т. Савич и Г. Раяло за вычисление констант реакции на аналоговой ЭВМ ЭМУ-10. 
ปี

ป⿱艹

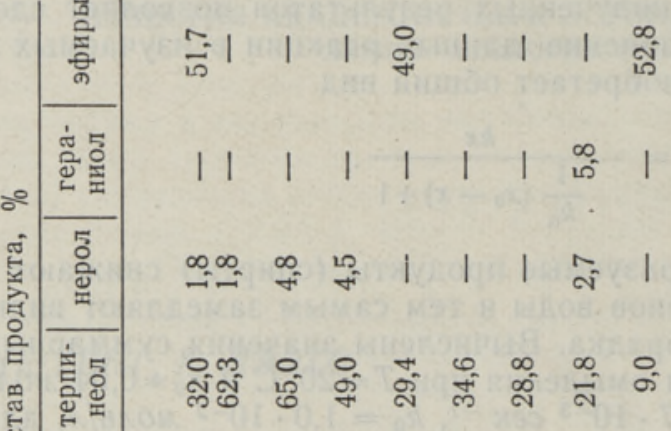

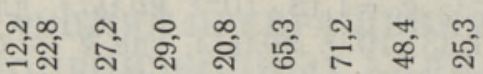

ज्ञल ले

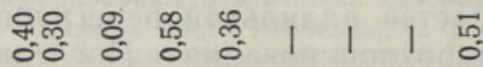

范

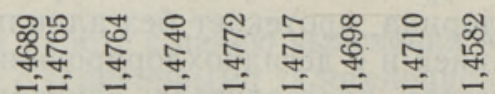

कृष्ठ $\frac{0}{6}$ เे

ํํำ $8 \circ$ ㅇํ

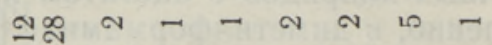

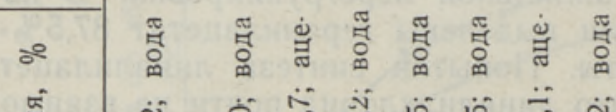

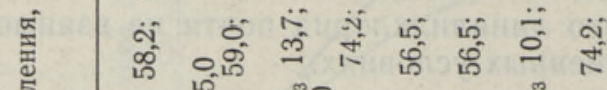

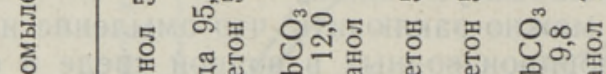

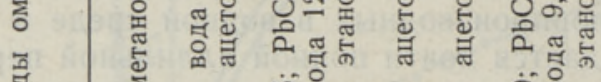

ठั

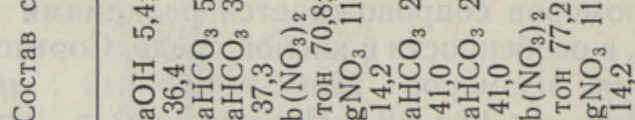

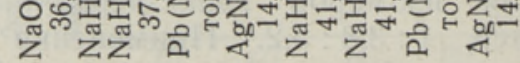

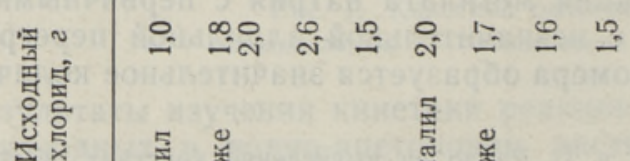

离总
ปัँ

$1 \mid \stackrel{\infty}{+}$

若

窎窝

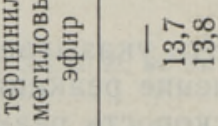

它:

के| ्ֻले 인

을

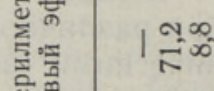

을 음

章

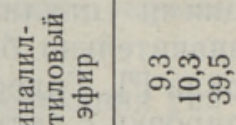

高

$\stackrel{2}{\stackrel{9}{*}}$

\begin{tabular}{|c|}
\hline 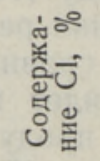 \\
\hline$\stackrel{\text { \&ి० }}{=}$ \\
\hline 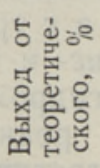 \\
\hline 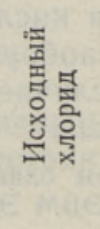 \\
\hline
\end{tabular}


первичных изомеров. Третичный изомер образует также циклические эфиры и продукты дегидрохлорирования. С ацетатом калия реагируют только первичные изомеры без аллильной перегруппировки.

Наблюдаемые закономерности, видимо, обусловлены размерами атакуемых ионов $\mathrm{OH}^{-}, \mathrm{CH}_{3} \mathrm{O}^{-}$и $\mathrm{CH}_{3} \mathrm{COO}^{-}$, а также электрическими и стерическими свойствами молекул изучаемых изомеров и образуемых продуктов.

\section{Экспериментальная часть}

1. Изучение кинетики омыления хлоридов. В 100 мл колбу с притертой пробкой помещали навеску хлорида $(0,2$ 2), 10 мл $3 \%$-ного водного раствора $\mathrm{NaHCO}_{3}$ и 20 мл ацетона. Содержимое колбы перемешивали при $20^{\circ} \mathrm{C}$ определенное время и оттитровывали 0,2 н. раствором соляной кислоты. Результаты приведены на рис. 1.

2. Омыление хлоридов в присутствии $\mathrm{NaHCO}_{3}$. В колбу, снабженную механической мешалкой и обратным холодильником, помещали 2,0 2 нерилхлорида, 2,0 г $\mathrm{NaHCO}_{3}, 20$ мл воды и 40 мл ацетона. Смесь нагревали при $60^{\circ}$ два часа. Затем при давлении 20 мм рт. ст. отгоняли ацетон и остаток экстрагировали эфиром; из эфирного раствора после сушки над $\mathrm{MgSO}_{4}$ выделяли продукт реакции перегонкой в вакууме. Результаты приведены в табл. 1.

3. Омыление хлоридов в присутствии $\mathrm{PbCO}_{3}$ и $\mathrm{Pb}\left(\mathrm{NO}_{3}\right)_{2} .2,6$ г нерилхлорида, 2,3 г $\mathrm{PbCO}_{3}, 0,6$ г $\mathrm{Pb}\left(\mathrm{NO}_{3}\right)_{2}, 2$ мл воды и 15 мл ацетона, интенсивно перемешивая, нагревали при $60^{\circ}$ один час. Выделение продукта производили как и в предыдущем опыте. Результаты приведены в табл. 1 .

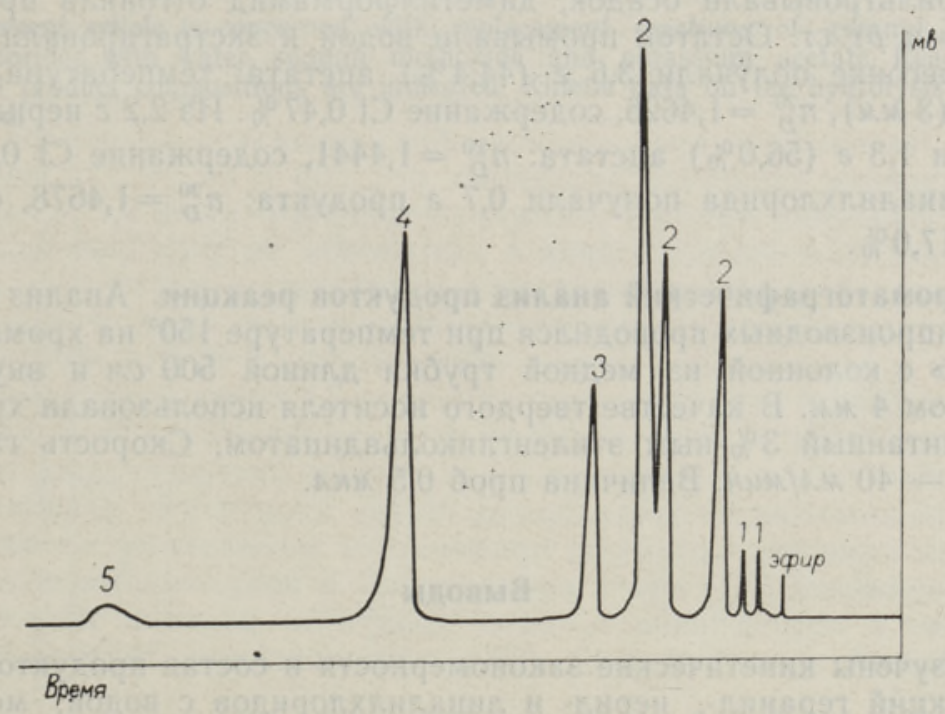

Рис. 2. Хроматограмма продукта омыления нерилхлорида в присутствии $\mathrm{NaOH}$ и метанола.

1 - терпены, 2 - метнловые эфиры терпеновых спиртов, 3 - линалоол, 4 - терпннеол, 5 - нерол.

4. Омыление хлоридов в присутствии $\mathrm{AgNO}_{3}$. K 1,5 г нерилхлорида, растворенного в 10 мл этанола, при охлаждении добавляли раствор из 
1,65 г $\mathrm{AgNO}_{3}, 3$ мл этанола и 2 мл воды. Смесь выдерживали при $0^{2}$ один час. Выделившееся хлористое серебро отфильтровывали, кислый фильтрат нейтрализовали с $\mathrm{NaHCO}_{3}$. Продукт выделяли, как в опыте 2. Результаты см. в табл. 1.

5. Омыление хлоридов в присутствии $\mathrm{NaOH}$. Смесь из 1,0 г нерилхлорида, 0,3 г $\mathrm{NaOH}, 4$ мл метанола и 2 мл воды нагревали при $60^{\circ}$ в гечение 12 . Метанол отгоняли при уменьшенном давлении, продукт экстрагировали эфиром, промывали и перегоняли. Результаты см. в табл. 1 и рис. 2.

6. Получение метиловых әфиров. 0,8 г $\mathrm{Na}$ растворяли в 50 мл абссолютного метанола и прибавляли 5,2 г галоидопроизводного. Смесь выдерживали при комнатной температуре. Затем метанол перегоняли при давлении 20 мм рт. ст. Остаток экстрагировали диэтиловым эфиром, промывали раствором кислоты до нейтральной реакции и высушивали. Результаты опытов приведены в табл. 2.

7. Получение ацетатов. 1. $\mathrm{K} 2,5$ г $\mathrm{CH}_{3} \mathrm{COOK}$ в 30 мл ацетона прибавляли 4,2 г геранилхлорида. Смесь перемешивали 4 ч при температуре $50^{\circ}$. Ацетон отгоняли, остаток экстрагировали эфиром и промывали водой. При перегонке получали 1,4 г продукта с $n^{20}=1,4762$ и содержанием хлора $14,7 \%$. Полученный продукт омыляли в водно-ацетоновом растворе в присутствии $\mathrm{NaHCO}_{3}$. Содержание в продукте омыления геранилацетата, по данным газовой хроматографии, составляло $13,6 \%$.

Увеличив время реакции до семи часов, содержание в продукте геранилацетата достигло $19,3 \%$.

2. К раствору 5,0 г ацетата калия в 50 мл диметилформамида прибавляли 7,7 г геранилхлорида в течение 20 мин при комнатной температуре. Смесь перемешивали один час при комнатной температуре и 4 ч при $50^{\circ}$. Отфильтровывали осадок, диметилформамид отгоняли при давлении 20 мм рт.ст. Остаток промывали водой и экстрагировали эфиром. При перегонке получали 3,6 г $(44,4 \%)$ ацетата: температура кипения $92-94^{\circ}(3 \mu м), n_{D}^{20}=1,4626$, содержание $\mathrm{Cl} 0,47 \%$. Из 2,2 г нерилхлорида получали 1,3 г $(56,0 \%)$ ацетата: $n_{D}^{20}=1,4441$, содержание $\mathrm{Cl} 0,92 \%$. Из

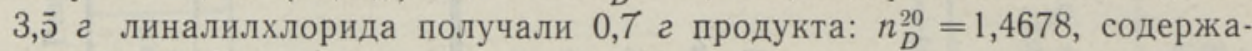
ние $\mathrm{Cl} 17,0 \%$.

8. Хроматографический анализ продуктов реакции. Анализ полученных оксипроизводных проводился при температуре $150^{\circ}$ на хроматографе «Хром-2» с колонной из медной трубки длиной $500 \mathrm{~cm}$ и внутренним диаметром 4 мм. В качестве твердого носителя использовали хромосорб $W$, пропитанный 3\%-ным этиленгликольадипатом. Скорость газа-носигеля $\mathrm{Ar}-40$ мл/мин. Величина проб 0,5 мкл.

\section{Выводы}

1. Изучены кинетические закономерности и состав продуктов обменных реакций геранил-, нерил- и линалилхлоридов с водой, метилатом натрия и ацетатом калия.

2. Установлен ряд закономерностей зависимости состава продуктов реакции от строения исходного галоидопроизводного, применяемого реагента и $\mathrm{pH}$ среды. 


\title{
ЛИТЕРАТУРА
}

1. Л ээт с К., ЖОХ, 28, 3096 (1958).

2. Л э э т с К., Изв. ӒН ЭССР, Хим. Геол., 17, 355 (1968).

3. T a n a k a J. et al., Nippon Kagaku Zasshi, 89, 875 (1968).

4. A s a h a r a T. et al., Kogyo Kagaku Zasshi, 72, 1529 (1969).

5. D e Wolf e R. H., Y oung W. G., Chem. Rews., 56, 813 (1956).

6. Л э э т С К., Т ен г С., Изв. АН ЭССР, Хим. Геол., 16, 292 (1967).

7. Тенг С., Л э э т с К., Изв. АН ЭССР, Хим. Геол., 20, 318 (1971).

8. Лээ тс К., Эрм А., Изв. АН ЭССР, Сер. физ.-матем. и техн. н., 13, 57 (1964).

9. Л э э т с К., Когерм а н А., Изв. АН ЭССР, Хим. Гесл., 18, 43 (1969).

10. Н а за ров И. Н., Гусев Б. П., Гуп а В. П., ЖОХ, 28, 1444 (1958).

\author{
Ннститут химии \\ Академии наук Эстонской ССР \\ Поступила в редакцию \\ 24/VI 1971
}

SIGNE TENG, K. LÄATS

\section{ALLOULSETE TERPEENSETE KLORIIDIDE OLEVIIMINE HAPNIKUUHENDITEKS}

Käsitletakse geranüül-, nerüül- ja linalüülkloriidi reaktsioone vee, naatriummetülaadi ja kaaliumatsetaadiga. On esitatud reaktsioonide tingimused ja määratud reaktsiooniproduktide koostis, samuti andmed hüdrolüüsi kineetika kohta.

SIGNE TENG, K. LÄATS

\section{CONVERSION OF ALLYLIC TERPENIC CHLORIDES TO OXYGEN CONTAINING DERIVATIVES}

The present article is concerned with replacement reactions of geranyl, neryl and linaloyl chlorides with water, sodium methoxide and potassium acetate. Reaction conditions and product compositions are indicated. Kinetic data on the hydrolysis reactions are reported. 